\title{
Links of Biomass of (Smilax Scobinicaulis) Dry Leaves and Daily Solar Radiation
}

\author{
Bing-Hua Liao \\ The key laboratory of ecological restoration in hilly areas, Henan province key laboratory of germplasm innovation \\ and utilization of eco-economic wood plant, Ping -ding-shan University, Henan province, China, 467000.2. State vital \\ laboratory of cotton biology, the vital laboratory of plant stress biology, School of Life science, Henan University, \\ Henan Province, China, 475004 \\ Email: $\underline{\text { lbh@henu.edu.cn }}$
}

Article History

Received: June 3, 2021

Revised: August 17, 2021

Accepted: August 21, 2021

Published: August 24, 2021

\begin{abstract}
(Smilax scobinicaulis) not only is a vital medicinal material plant by treating joint pain, but also it is a widely distributed wide plant species from 500m to $3100 \mathrm{~m}$ in Mei County of China. However, understanding links between total biomass of dry leaves and daily solar radiation is difficult. This study explained that it is an increasing of total biomass of dry leaves with increasing of daily solar radiation as well as links between total biomass of dry leaves and daily solar radiation is the significant positive connection from $20.578 \mathrm{~mol} / \mathrm{m}^{2} \cdot \mathrm{d}$ to $24.158 \mathrm{~mol} / \mathrm{m}^{2} \cdot \mathrm{d}$ along elevation from $500 \mathrm{~m}$ to $1500 \mathrm{~m}(P<0.01)$; it is a decreasing of this total biomass of dry leaves with increasing of daily solar radiation as well as the links between this total biomass of dry leaves and daily solar radiation is a significant negative connection from $24.15 \mathrm{~mol} / \mathrm{m}^{2} \cdot \mathrm{d}$ to $27.246 \mathrm{~mol} / \mathrm{m}^{2} \cdot \mathrm{d}$ along elevation from $1500 \mathrm{~m}$ to $3100 \mathrm{~m}(P<0.01)$. This research provides a series of areas ecological adaptation of daily solar radiation and six landscapes of this species. Therefore, this has vital theoretical and practical significance by medicinal plant species protection for better future of human health, ecosystem services and ecosystem functions along daily solar radiation gradient.
\end{abstract}

Keywords: Total biomass of dry leaves; daily solar radiation; links; medicinal; areas ecological adaptation.

\section{Introduction}

More and more researches have assessed the links between total biomass of dry leaves of medical plants and environments along elevation from total biomass of dry leaves (plant functional groups, biodiversity, height, total biomass of dry leaves) of medicinal plant species perspective by biodiversity researches (Table 1) [1-21], which based on better future of human heath by the finding medicinal plants. However, traditional medicinal plant species with typical history spanning over 1500 years, as well as areas ecological adaptation of total biomass of dry leaves of plant are unknown and values of medicinal species also cannot be utilized [3-12].

(Smilax scobinicaulis) not only is a vital medicinal material plant of treating joint pain, but also it is widely distributed wide specie along elevation from 500 to $3100 \mathrm{~m}$ by "big data" of our long-time investigation in $\mathrm{Mei}$ County. The species is belonging to Smilax L. genus of Liliaceae families of Monocotyledoneae in Angiospermae. However, understanding the links between total biomass of dry leaves of medical plants and dynamics of daily solar radiation along elevation is unknown, as well as the links between total biomass of dry leaves of plants and daily solar radiation is difficult finding along elevation and environmental factors [1-21] (Table 1).

And, elevation and environmental (daily solar radiation, disturbances) gradient also influence on total biomass of dry leaves (biomass, biodiversity, structure, et al.) of plant species in "big data" investigation of our long years researches. Explaining values of medicinal spices and the links between total biomass of dry leaves of medicinal plant and the daily solar radiation and different areas ecological adaptation of medical plants is a vital rule.

As such, there is not only the vital links between total biomass of dry leaves of species and daily solar radiation, but also there is a series of (good, better, best) this species areas ecological adaptation of daily solar radiation in six near-natural ecosystem for the better future of ecosystem structures (functions, composition, and services) and human future well-being and public health over spatial-temporal-environmental-disturbance scales (STEDS).

Abbreviation: STEDS, the spatial-temporal-environmental-disturbance scales. 
Sumerianz Journal of Agriculture and Veterinary

Table-1. Evaluation of Linkages between of Medicinal Plant Dynamics and Environmental Factors

\begin{tabular}{l|l}
\hline Assessments of links between multilevel medicinal plant and environs & Authors \\
\hline Links between biodiversity of plant functional groups and elevation at STEDS. & {$[21]$.} \\
\hline Links between biomass of medicinal herbs and elevation in wetland landscape. & {$[13]$.} \\
\hline Links between plant functional groups diversity and elevation in forest. & {$[14]$.} \\
\hline Links between plant functional groups and elevation in near-natural forests. & {$[16]$.} \\
\hline Links between number of medicinal tree species and elevation in forestation. & {$[15]$.} \\
\hline Links between average height of medicinal tree and elevation in landscapes. & {$[17]$.} \\
\hline Links between medicinal tree trunk volume and elevation in forests. & {$[18]$.} \\
\hline Links between number of tree community crown volume and elevation. & {$[19]$.} \\
\hline Links between number of individual specie's crown volumes and elevation. & {$[20]$.} \\
\hline Links between plant diversity and different disturbance of different elevation. & {$[1]$.} \\
Links between dry weight biomass of biomedical plant and elevations. & {$[2]$.} \\
Links between total biomass of fresh weight of medical plant and elevations. & {$[4]$.} \\
Links between vegetation coverage of biomedical plant and elevation. & {$[5]$.} \\
Links between pair's co-dominance abundance dominancy and elevation. & {$[6]$.} \\
Relation between plant average height of biomedical plant and elevation. & {$[7]$.} \\
Links between biomass of biomedical plant roots cuticle and elevation. & {$[8]$.} \\
Links between biomass of medical plant roots cuticle and daily solar radiation. & {$[9]$.} \\
Links between leafstalk biomass of biomedical plant and elevation. & {$[10]$.} \\
Links between biomass of biomedical plant stems cuticle and elevation. & {$[11]$.} \\
Links between Important Values of biomedical plant species and elevations & {$[3]$.} \\
Links between moisture content of biomass of biomedical plant and elevation. & {$[12]$.} \\
\hline
\end{tabular}

\section{Material and Methods}

\subsection{Environmental Condition, Situation of Special Typical Vegetation and Research Methods}

Typical area is local in three vegetation zones in China: firstly, evergreen vegetation in north subtropical zone; secondly, evergreen and deciduous coniferous and broad-leaved mixed forest in north subtropical and warm temperate transition; thirdly, deciduous vegetation in warm temperate zone by large total biomass of dry leaves investigation of medicinal plant. Thus, our research area is local in evergreen and deciduous coniferous and broadleaved mixed forest in north subtropical and warm temperate transition (landscape types included: urban, rural settlement, wetland, forest, grassland, farmland, river landscape as well as mixed zone landscape interaction each other) along elevation and environmental gradient in Mei County of China (Figure 1).

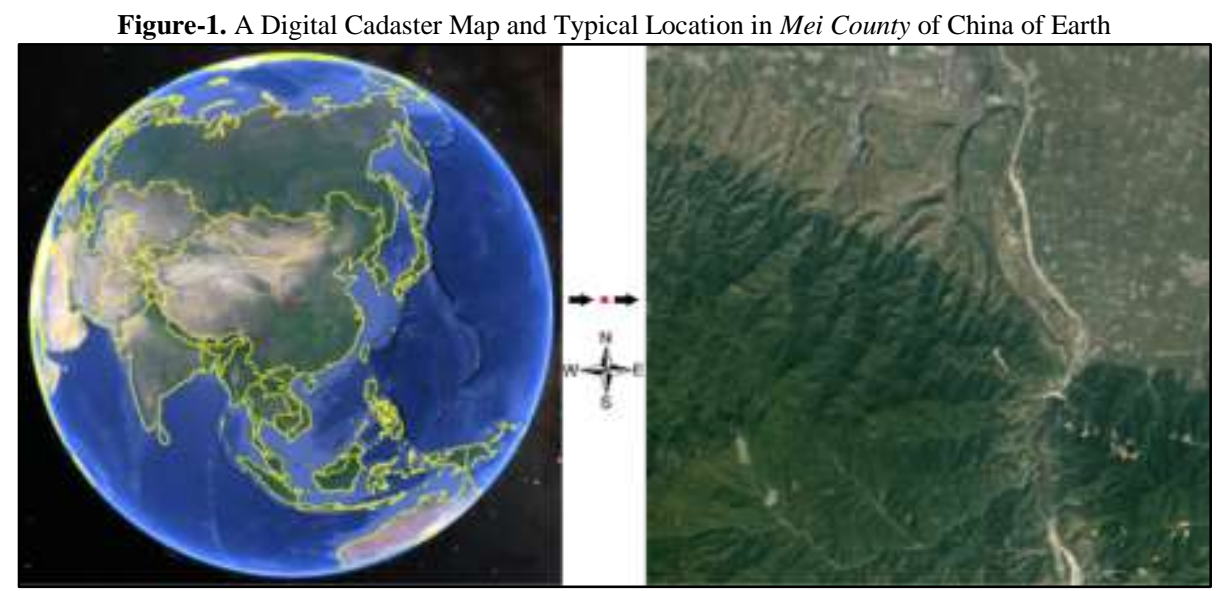

\subsection{Typical Location in Mei County of China of Earth}

There is a long time investigation by the links between medicinal plant species diversity and environments from 2005 to 2020. "Big data" included that dynamics of total biomass of dry leaves of medicinal plants or other index (Fu-niu Mountain, Yellow River, Ye County, Yi-luo River, Bai-gui Lake, Mei county, et al.) [1-20].

In short, it is a link between total biomass of (Smilax scobinicaulis) dry leaves and daily solar radiation, as well as it is a series of (good, better, best) natural landscapes areas ecological adaptation of daily solar radiation of this medical plant species by the "big data" of the ecological investigation, qualitative analysis, quantitative statistics, eco-rules, theories, methods and ways along elevation and other environmental gradient [3, 5-12, 22-28].

\section{Results and Analysis}

(Smilax scobinicaulis) not only is a vital medicinal material plant of treating joint pain, but also it is widely distributed wide plant species along elevation from 500 to $3100 \mathrm{~m}$ in natural ecosyleaves along elevation from $500 \mathrm{~m}$ to $3100 \mathrm{~m}$ in Mei County. However, understanding daily solar radiation effect on the links between this total biomass 
of dry leaves and daily solar radiation is very difficult. Using "big data" investigation, this research suggested there are three rules along increasing of daily solar radiation and elevation in Mei County of China:

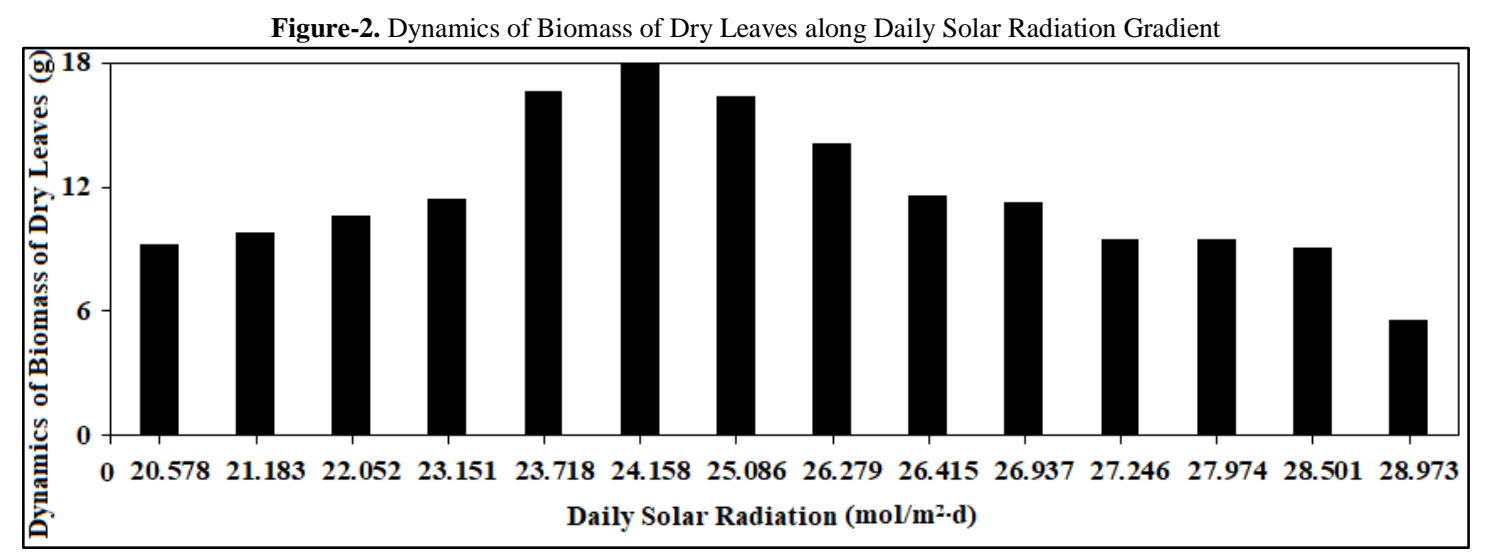

Firstly, this work proposed that not only it is an increasing of total biomass of dry leaves of this plant species with the increasing daily solar radiation, as well as it is a significant positive correlation between total biomass of dry leaves of this species and daily solar radiation from $20.578 \mathrm{~mol} / \mathrm{m}^{2} \cdot \mathrm{d}$ to $24.158 \mathrm{~mol} / \mathrm{m}^{2} \cdot \mathrm{d}(P<0.01)$ along elevation from $500 \mathrm{~m}$ to $1500 \mathrm{~m}$, but also it is a decreasing of total biomass of dry leaves of this plant species with the increasing of daily solar radiation, and it is a significant negative correlation between total biomass of dry leaves of this plant species and daily solar radiation from $24.158 \mathrm{~mol} / \mathrm{m}^{2} \cdot \mathrm{d}$ to $28.973 \mathrm{~mol} / \mathrm{m}^{2} \cdot \mathrm{d}(P<0.01)$ from $1500 \mathrm{~m}$ to $3100 \mathrm{~m}$. Because there is an increasing of daily solar radiation with increasing daily solar radiation and elevation is a significant positive correlation from $500 \mathrm{~m}$ to $3100 \mathrm{~m}$ elevation $(P<0.01)$ (Figure 2, 3; Table 2, 3).

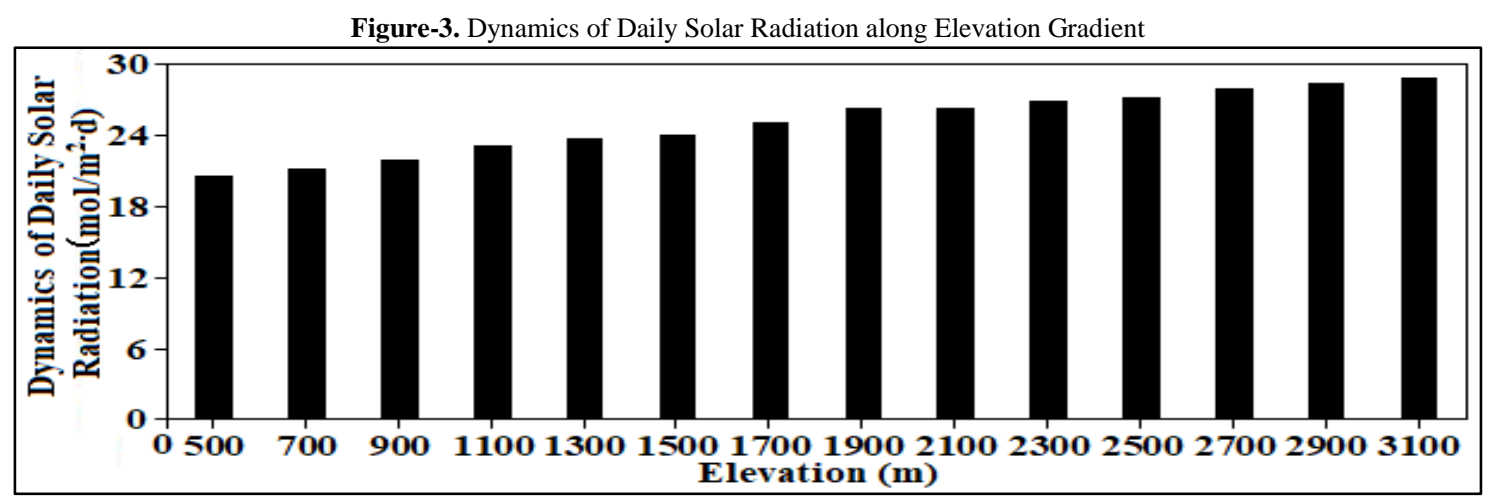

Firstly, this paper provided good areas ecological adaptation of daily solar radiation of this medical plant species is local in the areas ecological adaptation of daily solar radiation from $20.578 \mathrm{~mol} / \mathrm{m}^{2} \cdot \mathrm{d}$ to $28.973 \mathrm{~mol} / \mathrm{m}^{2} \cdot \mathrm{d}$ along elevation from $500 \mathrm{~m}$ to $3100 \mathrm{~m}$. Secondly, there are better areas ecological adaptation of daily solar radiation of this species from $23.151 \mathrm{~mol} / \mathrm{m}^{2} \cdot \mathrm{d}$ to $27.974 \mathrm{~mol} / \mathrm{m}^{2} \cdot \mathrm{d}$ along elevation gradient from $1100 \mathrm{~m}$ to $2700 \mathrm{~m}$, but also there are the best areas ecological adaptation of daily solar radiation of this medical plant species from $23.718 \mathrm{~mol} / \mathrm{m}^{2} \cdot d$ to $25.086 \mathrm{~mol} / \mathrm{m}^{2} \cdot \mathrm{d}$ along elevation from $1300 \mathrm{~m}$ to $1700 \mathrm{~m}$ at STEDS in Mei County (Figure 2, 3).

Table-2. Connection between Total Biomass of Dry Leaves and Daily Solar Radiation

\begin{tabular}{l|l}
\hline Daily Solar Radiation along Elevation Gradient & Plant Biomass of Dry Leaves \\
\hline Daily Solar Radiation From $500 \mathrm{~m}$ to $1500 \mathrm{~m}$ & $0.900^{*}$ \\
\hline Daily Solar Radiation From $150 \mathrm{~m}$ to $3100 \mathrm{~m}$ & $-0.970^{* *}$ \\
\hline Note: $*, P<0.05 ; * *, P<0.01$.
\end{tabular}

Thirdly, herein suggested that medicinal plant (Cremastra appendiculata) of treating joint pain is local in six natural landscape types (forest, mixed between grassland and forest, mixed between forest and wetland, mixed between forest and river, mixed between forest and urban, mixed between forest and rural settlement), because of there is result of dynamics of air and soil environments along elevation and daily solar radiation (Figure 1).

Table-3. Connection between Total Biomass of Dry Leaves Daily Solar Radiation Gradient

\begin{tabular}{l|l}
\hline Elevation $(\mathbf{m})$ & Elevation Gradient from $500 \mathrm{~m}$ to $3100 \mathrm{~m}$ \\
\hline Daily Solar Radiation & $0.992^{* *}$ \\
\hline Note: ${ }^{* *}, P<0.01$.
\end{tabular}

As such, this research finds typical (good, better, best) areas ecological adaptation of (Smilax scobinicaulis) of treating joint pain at daily solar radiation, and it is a link of total biomass of dry leaves and daily solar radiation. 


\section{Discussion}

Explaining dynamics of total biomass of dry leaves of medicinal species is very difficult [2-12, 22, 24-31]. Herein suggested three rules with biomass of dry leaves of this medicinal species along elevation and daily solar radiation:

Firstly, it is a significant positive connection between total biomass of dry leaves of this species and daily solar radiation along elevation from $500 \mathrm{~m}$ to $1500 \mathrm{~m}(P<0.01)$, because of it is an increasing of total biomass of dry leaves with increasing of daily solar radiation from $20.578 \mathrm{~mol} / \mathrm{m}^{2} \cdot \mathrm{d}$ to $24.158 \mathrm{~mol} / \mathrm{m}^{2} \cdot \mathrm{d}$. At the same time, it is a significant negative connection between Total biomass of dry leaves and daily solar radiation along elevation from along elevation from $1500 \mathrm{~m}$ to $3100 \mathrm{~m}(P<0.01)$, because of it is a decreasing of total biomass of dry leaves with increasing of daily solar radiation from $24.158 \mathrm{~mol} / \mathrm{m}^{2} \cdot \mathrm{d}$ to $27.246 \mathrm{~mol} / \mathrm{m}^{2} \bullet \mathrm{d}(P<0.01)$ at STEDS.

Secondly, this work provided good areas ecological adaptation along elevation from 500 to $3100 \mathrm{~m}$, the better areas ecological adaptation along elevation from 1100 to $2500 \mathrm{~m}$, and the best areas ecological adaptation of daily solar radiation of this medical plant along elevation from 1300 to $1700 \mathrm{~m}$ is local in Mei County (Figure 2, 3).

Thirdly, this research suggested that total biomass of dry leaves of this species of treating joint pain is local in six near-landscape types (forests, mixed landscapes between forestation and wetland, mixed landscapes between grassland and forestation, mixed landscapes between forest and urban, mixed landscapes between forest and river, mixed landscapes between forest and rural settlement) by "big data" along elevation gradient (Figure 1).

Therefore, herein has key theoretical and practical significance for the reasonable protection of total biomass of dry leaves of this species along the daily solar radiation and elevation gradient in six natural landscapes. Because of this plant species not only is a vital widely distributed wide medicinal plant species of treating joint pain, but also there are three rules by the links between total biomass of dry leaves of this species and daily solar radiation. In short, regional planners need regulation a lot of landscape sustainability based on researches on total biomass of dry leaves of medical plant species (biodiversity, composition, structure, et al.) by the "eco-big data" investigation, qualitative analysis, quantitative statistics, human cognitive ecological linguistic rules and theory of the links between biodiversity and environments in the global, local, regional landscapes for the better future of human health and ecosystem leaves stability and functions along daily solar radiation, environments [22-28, 30-32].

Therefore, herein provides a series of areas ecological adaptation of daily solar radiation and six landscapes of this species, which has vital theoretical and practical significance by medicinal plant species protection for better future of human health, ecosystem services along daily solar radiation, elevation or other environmental gradients (e.g., light, heat, water, soil nutrients, air, topography and landform).

\section{Future Work}

Indeed, a better regional regulator and local government need a better planning and regulation a lot of medicinal plant management eco-sustainability of ecosystems by the researches on biomass of leafstalk along elevation and environments with dynamics of biodiversity in the global, local, regional natural ecosystem types with the ways "big data" investigation, quantitative statistics for better future of vegetation and human well-being [29, 33-43].

Next work this research finding is a basal knowledge for the better understanding the interrelations between environmental factors and multilevel diversity (e.g., landscapes, population, communities, and species level) [44-48]. Future human ecological cognitive linguistic theory [49] must understand the different environmental factors influencing the multilevel species ecological traits (such as plant leaves, plant stem barks, plant roots [50], green ecological habitat resources and genetic breeding [51], synthetic metabolism [52], multilevel diversity [53], adventitious roots [54], microbiome shift [55], anti-infective plants [56] for decrease ecosystem collapse and species diversity loss [57] by green chemical approach [58] and phytochemistrym, therapeutics methods [59].

\section{Conclusion}

This work firstly find that (Smilax scobinicaulis) not only is a vital medicinal material plant by treating joint pain, but also provides a series of areas ecological adaptation of daily solar radiation and six landscapes (wetlands, water, grasslands, forests, countryside and farmlands) of this species. Just as it is a significant positive connection between total biomass of dry leaves and daily solar radiation from $20.578 \mathrm{~mol} / \mathrm{m}^{2} \cdot \mathrm{d}$ to $24.158 \mathrm{~mol} / \mathrm{m}^{2} \cdot \mathrm{d}$ along elevation from $500 \mathrm{~m}$ to $1500 \mathrm{~m}(P<0.01)$; it is a significant negative connection between total biomass of dry leaves and daily solar radiation is a significant connection from $24.15 \mathrm{~mol} / \mathrm{m}^{2} \cdot \mathrm{d}$ to $27.246 \mathrm{~mol} / \mathrm{m}^{2} \cdot \mathrm{d}$ along elevation from $1500 \mathrm{~m}$ to $3100 \mathrm{~m}(P<0.01)$. Therefore, this work firstly has been found interrelations between total biomass of dry leaves and daily solar radiation. It is a theoretical and practical significance by medicinal plant species protection by treating joint pain for better human-wellbeing and conservation of medicinal material specie.

\section{Acknowledgement}

This work was supported by A Grade of Key Disciplines of Environmental Science Foundation, B Grade of Key Disciplines of Mistrials Science of Ping-Ding-shan University in China; Science and Technology Department of He'nan Province Foundation (KJT-17202310242; 092102110165) ; Subprojects by Intergovernmental Platform on Biodiversity and Ecosystem Services (IPBES); better ideas of planners of "1st Biotechnology World Congress" in 2011, "2st Biotechnology World Congress" in 2012, "3st Biotechnology World Congress" in 2013 is appreciated. 


\section{References}

[1] Liao, B., 2014. "A new model of dynamic of plant diversity in changing farmlands, implications for the management of plant biodiversity along differential environmental gradient in the spring." African Journal of Environmental Science and Technology, vol. 8, pp. 171- 177.

[2] Liao, B., 2020. "Links between dry weight biomass of (cremastra appendiculata) of biomedical and pharmaceutical plant and elevations by long-time investigation of big data." World Journal of Pharma ceutical Research, vol. 9, pp. 14-21.

[3] Liao, B., 2020. "Links between Important Values of (Cremastra appendiculata) and elevations by long-time investigation and qualitative analysis and quantitative statistics of Big." International Journal of Science and Research Archive, vol. 1, pp. 44-50.

[4] Liao, B., 2020. "Links between total biomass of fresh weight of (cremastra appendiculata) and elevation in biomedical and pharmaceutical plant science by long-time investigation of big data." European Journal of Biomedical and Pharmaceutical Sciences, vol. 7, pp. 83-88.

[5] Liao, B., 2020. "Links between vegetation coverage of (cremastra appendiculata) and elevation in biomedical and pharmaceutical plant science by big data of long-time investigation." World Journal of Pharmaceutical Research, vol. 9, pp. 72-82.

[6] Liao, B., 2020. "Links between species pair's co-dominance abundance dominancy of (cremastra appendiculata) of biomedical and pharmaceutical plant and elevations." European Journal of Biomedical and Pharmaceutical Sciences, vol. 7, pp. 54-59.

[7] Liao, B., 2020. "Relation between plant average height of (Cremastra appendiculata) and elevations." GSC Advanced Research and Reviews, vol. 5, pp. 104-110.

[8] Liao, B., 2020. "Links between Biomass of (Cremastra appendiculata) Roots Cuticle and Elevation along Elevation Gradient by Big Data of long-time wild investigation in Mei County." International Journal of Applied Science, vol. 3, pp. 1-7.

[9] Liao, B., 2020. "Links between biomass of (cremastra appendiculata) roots cuticle and daily solar radiation by big data of long-time wild investigation in mei county." EAS Journal of Pharmacy and Pharmacology, vol. 2, pp. 205-210.

[10] Liao, B., 2020. "Links between leafstalk biomass of (cremastra appendiculata) and elevation by big data of long-time wild investigation in mei-county." Journal of Drug Delivery and Therapeutics, vol. 10, pp. 5560 .

[11] Liao, B., 2020. "Links between biomass of (cremastra appendiculata) stems cuticle and elevation by big data of long-time wild investigation in mei county." Sumerianz Journal of Agriculture and Veterinary, vol. 3, pp. 178-182.

[12] Liao, B., 2021. "Links between moisture content of biomass of (cremastra appendiculata) and elevation by long-time investigation and qualitative analysis and quantitives statistics of big data." January of Biological Innovative, vol. 10, pp. 208-216.

[13] Liao, B. and Ding, S. Y., 2011. "Dynamics of plant functional groups composition along environmental gradients in the typical area of Yi-Luo River watershed." African Journal of Biotechnology, vol. 10, pp. 14485-14492.

[14] Liao, B. and Ding, S. Y., 2011. "Dynamics of environmental gradients on plant functional groups composition on the northern slope of the Fu-Niu Mountain Nature Reserve." African Journal of Biotechnology, vol. 10, pp. 18939-18947.

[15] Liao, B. and Liu, M., 2019. "Dynamics of (Sophora japonica) Community's Tree Individual Number along Elevation Gradient in Ye County. International." Journal of Pharmacognosy and Pharmaceutical Sciences, vol. 1, pp. 1-4.

[16] Liao, B. and Liu, Q., 2014. "Dynamics of environmental gradients on plant functional groups composition species in near-natural community ecological restoration on the southern slope of the Fu-Niu Mountain Nature Reserve." Journal of Science, vol. 4, pp. 306-312.

[17] Liao, B. and Liu, Y., 2019. "Elevation dynamics of (sophora japonica) community's height in ye county." International Journal of Research Pharmaceutical and Nano Sciences, vol. 8, pp. 48 -54.

[18] Liao, B. and Liu, Y., 2019. "Dynamics of 18 (sophora japonica) tree community's total trunk volume along elevation gradient in ye county." International Journal of Current Advanced Research, vol. 8, pp. 1906319066.

[19] Liao, B. and Liu, Y., 2019. "Dynamics Crown Volume of 18 (Sophora japonica) Tree Communities along Elevation Gradient in Ye County." Open Journal of Ecology, vol. 9, pp. 209 -215.

[20] Liao, B. and Liu, Y., 2019. "Dynamics of 18 (sophora japonica) tree individual specie's crown volume along elevation gradient in ye county." International Journal of Research Pharma -ceutical and Nano Sciences, vol. 8, pp. 62-68.

[21] Liao, B. and Wang, X. H., 2010. "Plant functional group classifications and a generalized hierarchi -cal framework of plant functional traits." African Journal of Biotechnology, vol. 9, pp. 9208-9213.

[22] Burin, G. and Jr, P. R., 2021. "Macroevolutionary stability predicts interaction patterns of species in seed dispersal networks." Science, vol. 372, pp. 733-737.

[23] Das, A. and Kamal, S., 2012. "The root endophyte fungus Piriformospora indica leads to early flowering, higher biomass and altered secondary metabolites of the medicinal plant, Coleus forskohlii." Plant Signaling Behavior, vol. 7, pp. 103-112. 
[24] Gul, R. and Nisar, A., 2019. "Photodependent somatic embryogenesis from non-embryogenic calli and its polyphenolics content in high-valued medicinal plant of Ajuga bracteosa." Journal of Photochemistry and Photobiology B Biology, vol. 190, pp. 59-65.

[25] Izuishi, Y. and Isaka, N., 2020. "Apple latent spherical virus (ALSV)-induced gene silencing in a medicinal plant, Lithospermum erythrorhizon." Scientific Reports, vol. 10, pp. 1-9.

[26] Laura, H., 2005. "Biodiversity: saving Florida panther makes sense." Nature, vol. 438, p. 156.

[27] Lombardo, U. and Iriarte, J., 2020. "Early Holocene crop cultivation and landscape modification in Amazonia." Nature, vol. 581, pp. 190-193.

[28] Singh, S. P. and Gaur, R., 2016. "Evaluation of antagonistic and plant growth promoting activities of chitinolytic endophytic actinomycetes associated with medicinal plants against Sclerotiumrolfsii in chickpea." Journal of Applied Microbiology, vol. 121, pp. 506-518.

[29] Das, K. and Dang, R., 2005. "Interaction between phosphorus and zinc on the biomass yield and yield attributes of the medicinal plant stevia (Stevia rebaudiana)." Scientific World Journal, vol. 5, pp. 390-395.

[30] Huma, A. and Khan, M. A., 2019. "Production of biomass and medicinal metabolites through adventitious roots in Ajuga bracteosa under different spectral lights." Journal of Photochemistry and Photobiology. B, biology, vol. 193, pp. 109-117.

[31] Renner, S. C., 2005. "Biodiversity: there's a role to be played by 'museum-keepers' too." Nature, vol. 438, p. 914.

[32] Larsen, H. O., 2002. "Commercial medicinal plant extraction in the hills of Nepal: local management system and ecological sustainability." Environmental Management, vol. 29, pp. 88-101.

[33] Cotto, O. and Wessely, J., 2017. "A dynamic eco-evolutionary model predicts show response of alpine plants to climate warming." Nature Communications, vol. 8, pp. 1-9.

[34] Elkins, A. C. and Deseo, M. A., 2019. "Development of a validated method for the qualitative and quantitative analysis of cannabinoids in plant biomass and medicinal cannabis resin extracts obtained by super-critical fluid extraction." Journal of Chromatography B, vol. 1109, pp. 76- 83.

[35] Grass, I. and Kubitza, C., 2020. "Trade-offs between multifunctionality and profit in tropical smallhoder landscapes." Nature Communications, vol. 11, pp. 1-13.

[36] Harris, J. and Kotiaho, J. S., 2018. "New jargon seeping slowly into biodiversity world." Nature, vol. 562, p. 39.

[37] Igor, V. and Jayanth, R. B., 2004. "The stability of forest biodiversity." Nature, vol. 427, pp. 696-697.

[38] Jacquelie, O. and Bernhard, S., 2020. "Terrestrial land-cover type richness is positively linked to landscape level functioning." Nature Communications, vol. 11, pp. 1-10.

[39] Kenneth, G. C. and Patricio, G., 2020. "A global perspective on sustainable intensification research." Nature Sustainability, vol. 3, pp. 262-268.

[40] Kumar, V. and Roy, B. K., 2018. "Population authentication of the traditional medicinal plant Cassiatora L. based on ISSR markers and FTIR analysis." Scientific Reports, vol. 8, pp. 1-11.

[41] Opgenoorth, L. and Hotes, S., 2014. "IPEPS: Biodiversity panel should play by rules." Nature, vol. 506, p. 159.

[42] Song, H. and Payne, S., 2009. "Spatiotemporal modulation of biodiversity in a synthetic chemicalmediated ecosystem." Nature Chemical Biology, vol. 5, pp. 929-935.

[43] Waldron, A. and Miller, D. C., 2017. "Reductions in global biodiversity loss predicted rom conservation spending." Nature, vol. 551, pp. 364-367.

[44] Liao and Georgina, M. M., 2019. "Limits to agricultural land for retaining acceptable levels of local biodiversity." Nature Sustainability, vol. 2, pp. 491-498.

[45] Liao, B. and Boeck, H. J. D., 2015. "Gap formation following climatic events in spatially structured plant communities." Scientific Reports, vol. 5, p. 11721.

[46] Liao, B. and Bogaert, J., 2015. "Species interactions determine the spatial mortality patterns emerging in plant communities after extreme events." Scientific Reports, vol. 5, p. 11229.

[47] Liao, B. and Chen, J. H., 2016. "An extended patch-dynamic framework for food chains in fragmented landscapes." Scientific Reports, vol. 6, p. 33100.

[48] Liao, B. and Ying, Z. X., 2015. "Species extinction thresholds in the face of spatially correlated periodic disturbance." Scientific Reports, vol. 5, p. 15455.

[49] Zhu, D. M. and Liao, B., 2015. "A dynamical system of human cognitive linguistic theory in learning and teaching of the typical university in Henan Province." International Journal of Pharmacy and Therapeutics, vol. 6, pp. 4-6.

[50] Jin, D. and Dai, K. P., 2020. "Secondary metabolites profiled in cannabis inflorescences, leaves, stem barks, and roots for medicinal purposes." Scientific Reports, vol. 10, pp. 1-14.

[51] Yang, Y. and Sun, M., 2020. "Germplasm resources and genetic breeding of Paeonia: a systematic review." Horticulture Research, vol. 7, pp. 1-19.

[52] Joseph, P. N., 2010. "Synthetic metabolism goes green." Nature, vol. 468, pp. 380-381.

[53] Ibisch, P. L. and Jennings, M. D., 2005. "Biodiversity needs the help of global change managers, not museum- keepers." Nature, vol. 438, p. 156.

[54] Saeed, S. and Ali, H., 2017. "Impacts of methyl jasmonate and phenyl acetic acid on biomass accumulation and antioxidant potential in adventitious roots of Ajuga bracteosa Wall ex Benth., A high valued endangered medicinal plant." Physiol. Mol. Biol. Plants, vol. 23, pp. 229- 237. 
[55] Martina, K. and Sabine, E., 2019. "Deciphering the microbiome shift during fermentation of medicinal plants." Scientific Reports, vol. 9, pp. 1-11.

[56] Schultz, F. and Anywar, G., 2020. "Targeting ESKAPE pathogens with anti-infective medicinal plants from the Greater Mpigi region in Uganda." Scientific Reports, vol. 10, pp. 1-19.

[57] MacDougall, A. S. and McCann, K. S., 2013. "Diversity loss with persistent human disturbance increases vulnerability to ecosystem collapse." Nature, vol. 494, pp. 86-89.

[58] Sergiy, L. and Olesia, S., 2019. "Integrated green chemical approach to the medicinal plant carpobrotus edulis processing." Scientific Reports, vol. 9, pp. 1-12.

[59] Mohanraj, K. and Karthikeyan, B. S., 2020. "IMPPAT: A curated database of Indian medicinal plants, phytoche -mistry and therapeutics." Scientific Reports, vol. 8, pp. 1-17. 